\title{
Responses to Predictable versus Random Temporally Complex Stimuli from Single Units in Auditory Thalamus: Impact of Aging and Anesthesia
}

\author{
Rui Cai, ${ }^{-B e n}$ D. Richardson, and $\$ Donald M. Caspary \\ Southern Illinois University School of Medicine, Department of Pharmacology, Springfield, Illinois 62794
}

Human aging studies suggest that an increased use of top-down knowledge-based resources would compensate for degraded upstream acoustic information to accurately identify important temporally rich signals. Sinusoidal amplitude-modulated (SAM) stimuli have been used to mimic the fast-changing temporal features in speech and species-specific vocalizations. Single units were recorded from auditory thalamus [medial geniculate body (MGB)] of young awake, aged awake, young anesthetized, and aged anesthetized rats. SAM stimuli were modulated between 2 and $1024 \mathrm{~Hz}$ with the modulation frequency ( $\mathrm{fm}$ ) changed randomly (RAN) across trials or sequentially (SEQ) after several repeated trials. Units were found to be RAN-preferring, SEQ-preferring, or nonselective based on total firing rate. Significant anesthesia and age effects were found. The majority $(86 \%)$ of young anesthetized units preferred RAN SAM stimuli; significantly fewer young awake units $(51 \%, p<0.0001)$ preferred RAN SAM signals with $16 \%$ preferring SEQ SAM. Compared with young awake units, there was a significant increase of aged awake units preferring SEQ SAM $(30 \%, p<0.05)$. We examined RAN versus SEQ differences across $f m s$ by measuring selective $\mathrm{fm}$ areas under the rate modulation transfer function curve. The largest age-related differences from awake animals were found for mid-to-high fms in MGB units, with young units preferring RAN SAM while aged units showed a greater preference for SEQ-presented SAM. Together, these findings suggest that aged MGB units/animals employ increased top-down mediated stimulus context to enhance processing of "expected" temporally rich stimuli, especially at more challenging higher fms.

Key words: aging; anesthesia; awake; SAM sequence detection; thalamus

Significance Statement

Older individuals compensate for impaired ascending acoustic information by increasing use of cortical cognitive and attentional resources. The interplay between ascending and descending influences in the thalamus may serve to enhance the salience of speech signals that are degraded as they ascend to the cortex. The present findings demonstrate that medial geniculate body units from awake rats show an age-related preference for predictable modulated signals relative to randomly presented signals, especially at higher, more challenging modulation frequencies. Conversely, units from anesthetized animals, with little top-down influences, strongly preferred randomly presented modulated sequences. These results suggest a neuronal substrate for an agerelated increase in experience/attentional-based influences in processing temporally complex auditory information in the auditory thalamus.

\section{Introduction}

Age-related hearing loss is the cumulative effect of aging on hearing and affects about two-thirds of individuals over 75 years old

\footnotetext{
Received May 2, 2016; revised Aug. 22, 2016; accepted Aug. 27, 2016.

Author contributions: R.C. and D.M.C. designed research; R.C. and B.D.R. performed research; R.C. contributed unpublished reagents/analytic tools; R.C. analyzed data; R.C., B.D.R., and D.M.C. wrote the paper.

This work was supported by National Institute on Deafness and Other Communication Disorders Grant DC000151. We thank Drs. Tom Brozoski and Daniel Llano for their careful reading and comments on the manuscript and Brandon Young for Matlab programing. We give special thanks to the National Institute on Aging for providing Fischer $344 \times$ Brown Norway rats.

The authors declare no competing financial interests.
}

(Bainbridge and Wallhagen, 2014; Gordon-Salant, 2014). The central auditory pathway responds to age-related peripheral changes in part by selective down-regulation of inhibitory circuits, reducing temporal accuracy (Strouse et al., 1998; Caspary et al., 2008; Anderson et al., 2012). This affects the accuracy of the upstream acoustic message, especially in complex acoustic envi-

Correspondence should be addressed to Donald M. Caspary, Department of Pharmacology, P.0. Box 19629, Springfield, IL 62794-9629. E-mail: DCASPARY@SIUMED.EDU.

B.D. Richardson's present address: Washington State University, Integrative Physiology and Neuroscience, Pullman, WA 99164

DOI:10.1523/JNEUROSCI.1454-16.2016

Copyright $\odot 2016$ the authors $\quad 0270-6474 / 16 / 3610696-11 \$ 15.00 / 0$ 
ronments, which likely reflects impaired, jittered processing of acoustic information (Dubno et al., 1984; Moore et al., 1992; Fitzgibbons and Gordon-Salant, 1994; Schneider et al., 1994; Snell, 1997; Strouse et al., 1998; Tremblay et al., 2002, 2003; Ostroff et al., 2003; Caspary et al., 2008). Human aging studies suggest that, to compensate for degraded neural representation of acoustic information, the brain makes use of cortical, top-down resources in efforts to maintain accurate identity of important temporally complex signals, such as speech (Harris et al., 2012; Mattys and Scharenborg, 2014).

Sinusoidal amplitude-modulated (SAM) stimuli have been used to examine how temporally modulated "speech-like" sounds are coded by single neural elements, from the cochlear nucleus to the auditory cortex (Joris et al., 2004). In the auditory thalamus, the temporal coding strategy of SAM stimuli was reported to transfer from time-locking to a more efficient sparse rate code at higher modulation frequencies ( $\mathrm{fms}$ ), which might reflect interactions between top-down and bottom-up processing (Lu et al., 2001; Bartlett and Wang, 2007; Wang et al., 2008; Cai and Caspary, 2015).

To accurately extract salient information from the environment, cortical and brainstem auditory structures have developed mechanisms to selectively identify novel/important stimuli (Antunes et al., 2010; Nelken, 2014; Ayala et al., 2015). As a key gateway to the cortex, thalamocortical neurons in the medial geniculate body (MGB) show stimulus-specific adaptation (SSA) in response to simple pure-tone stimuli, responses that are relatively unaffected by anesthesia, sleep, and aging (Ulanovsky et al., 2003; von der Behrens et al., 2009; Richardson et al., 2013b; Nir et al., 2015). These results using simple stimuli suggest a bottom-up origin of SSA. Recent reviews point to differences between novelty detection at the level of the cortex, which likely incorporates postattentive and cognitive information, relative to novelty detection in the brainstem-ascending central auditory nervous system (CANS), which may be more automatic (Nelken, 2014; Malmierca et al., 2015).

Top-down signals of cortical origin, which project throughout the CANS, serve to identify the salience and contextual importance of communication calls and danger signals (Harris et al., 2012; Llano, 2013; Helfer and Freyman, 2014; Stebbings et al., 2014). Increased use of top-down resources have long been observed in older individuals performing auditory tasks (Ostroff et al., 2003; Fakhri et al., 2012; Leung et al., 2013). Multiple classes of anesthetics selectively impair top-down feedback but not feedforward (bottom-up) processing (Ferrarelli et al., 2010; Casali et al., 2013; Mashour, 2014). In essence, either enhancing (such as in aging) or weakening (such as in anesthesia) top-down processing could affect processing of modulated sound sequences.

Neurons in the auditory cortex are reported to be sensitive to the detailed structure of sound sequences over timescales of minutes (Yaron et al., 2012). Studies investigating complex eventrelated potentials found age-related decreased neural adaptation in older adults (Leung et al., 2013). The present study investigated the impact of experimentally knocking down (via anesthesia) descending top-down pathways on SAM sequence preference. We also investigated the effect of age on thalamic units' responses to sequence-modified SAM stimuli. We hypothesize that with increasing age, corticothalamic and corticotectal top-down signals can modify automated upstream processes used to filter out repetitive uninformative signals. This allows attentive and cognitive processes to more actively shape and identify important ascending signals. Consistent with this hypothesis, we predicted that MGB neurons from aged animals would show increased

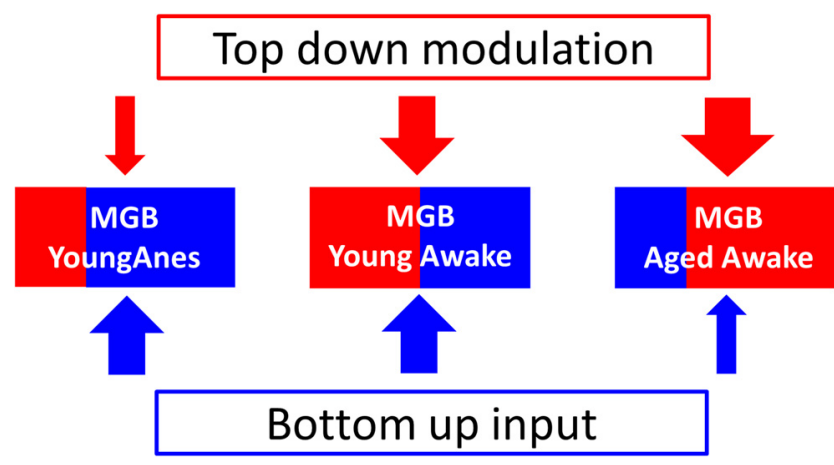

Figure 1. Bottom-up/top-down circuits among young anesthetized, young awake, and aged awake rats. Both bottom-up and top-down circuits are used to recognize/identify salient acoustic information from one's environment. We propose that MGB neurons in young awake/ alert rat balance selective temporally rich bottom-up (blue arrow) inputs with top-down (red arrow) circuits, which help the animal identify complex temporal information. Responses from MGB neurons in anesthetized rats appear dominated by bottom-up adaptive processes, suggesting a reduction of top-down processing. We posit that the degraded up-stream temporal responses seen in the aged brainstem result in increased top-down resources needed to maintain salience by enhancing the responses to the next expected signal.

preference for sequentially (SEQ) or predictably presented SAM stimuli, while MGB neurons from awake and anesthetized young rats would prefer randomly (RAN)/interleaved strings of SAM stimuli (Fig. 1).

\section{Materials and Methods}

Male Fischer $344 \times$ Brown Norway $(F B N)$ rats from the National Institute on Aging, Aging Rodent Resource Colony supplied by Charles River were individually housed on a reverse 12:12-h light-dark cycle with ad libitum access to food and water. FBN rats have a long life-span and less tumor load than other commonly used rat models, and are available through rodent resources at the National Institute of Aging (nia.nih.gov/ research/scientific-resources\#rodent). Procedures were in accordance with guidelines of and protocols approved by the Southern Illinois University School of Medicine Laboratory Animal Care and Use Committee.

Acoustic brain stem response recording. Before surgery, acoustic brain stem response (ABR) threshold testing was completed on all rats to ensure that animals used in the present study [young adult, (4-6 months old) and aged (28-30 months old)] had hearing threshold levels consistent with those observed in previous studies, specifically, a $10-25 \mathrm{~dB}$ threshold shift for aged rats (Wang et al., 2009). For ABRs, rats were anesthetized with an intramuscular injection of a 3:1 mixture of ketamine and xylazine at a dose of $7 \mathrm{mg} / \mathrm{kg}$ xylazine and $105 \mathrm{mg} / \mathrm{kg}$ ketamine (dose for aged rats was reduced by $\sim 20 \%$ ). ABRs were collected as previously described (Wang et al., 2009): 3 ms duration with $1 \mathrm{~ms}$ rise/decay clicks and pure tones at 4, 8, 12,16,24, and $32 \mathrm{kHz}$ presented 512 times at 20/s. A recording electrode was inserted into the skin over vertex, with the reference electrode inserted just under the left mastoid and the ground wire attached to the hind leg. ABR signal gain totaled 200,000 $\times$ with filtering between 0.3 and $3 \mathrm{kHz}$. Absolute thresholds were determined for the ABR wave I for each rat at each frequency by an experimenter blinded to the age of the subject. ABRs and single-unit recording experiments were completed in a double-wall soundproof booth (Industrial Acoustic).

Awake preparation. Rats were allowed to recover for $3 \mathrm{~d}$ after $\mathrm{ABR}$ testing before beginning acclimatization to the recording chamber. One week before surgery, rats were acclimated to a modified Experimental Conditioning Unit (Braintree Scientific) with ad libitum access to water using a food reward (Froot Loop) until they remained quiet/still for $\leq 3 \mathrm{~h}$.

VersaDrive4 tetrode drives (Neuralynx) were assembled and loaded with tetrodes as previous described (Richardson et al., 2013b; Kalappa et al., 2014). Each tetrode wire was gold-electroplated to an impedance between 1.0 and $1.5 \mathrm{M} \Omega$ sampled at $1 \mathrm{kHz}$ (nanoZ, Neuralynx). Drives were sterilized with ethylene oxide before implantation. Surgery details 
were similar to those of Richardson et al. (2013b) and Kalappa et al. (2014): 1 d before surgery, acetaminophen $(4.5 \mathrm{mg} / \mathrm{ml})$ was provided via the rat's drinking water and continued until the second day after surgery to alleviate the pain. Surgery was performed under anesthesia, intramuscular ketamine (105 $\mathrm{mg} / \mathrm{kg}$ ) and xylazine $(7 \mathrm{mg} / \mathrm{kg})$, with the aged dose reduced by $\sim 20 \%$. Rats were given sterile saline $(3 \mathrm{ml})$ subcutaneously, placed on a thermostatically controlled heating pad (Harvard Apparatus) and set in a Kopf stereotaxic frame with a nose cone and chin bars. $\mathrm{O}_{2}$ blood saturation level and heart rate were monitored (PulseSense Vet, Nonin Medical) during the surgery. Oxygen was administered continuously to maintain $95-100 \%$ blood saturation, and isoflurane (1-2.5\%) was administered using a gaseous anesthesia system (VetEquip). The level of anesthesia was adjusted based on the presence of pedal withdrawal or elevated heart rate.

Under sterile conditions, the skull surface was exposed and anchor screws were set in place. A 2.3-mm-diameter craniotomy hole was drilled over the left occipitoparietal cortex, dorsal to the MGB (5.5-5.7 mm of bregma and 3.5-3.8 $\mathrm{mm}$ of midline), and dura carefully removed. A ground wire was attached to a reference screw placed in the anterior right frontal bone that made contact with the dura, and the tetrode drive was slowly advanced to a depth of $4.5-5 \mathrm{~mm}$, placing the four tetrode tips just dorsal to the MGB. Dental acrylate cement was added around the anchor screws and drive, encapsulating the entire drive with the exception of the drive screws and pins. Total weight of the tetrode drive and dental cement was $<10 \mathrm{~g}$. Mounting the tetrode drive did not appear to alter animal behavior or demeanor, with postmortem examination indicating little damage to the surface of the brain. Following surgery, triple antibiotic ointment was applied to the edge of the headcap and wound and an additional $2-3 \mathrm{ml}$ of sterile saline was administered subcutaneously. The animal was exposed to $100 \%$ oxygen and kept on a heating pad throughout recovery until ambulatory (Richardson et al., 2013b; Kalappa et al., 2014). The tetrode drive was coupled to an 18-pin (16 single wires, 2 ground) VersaDrive4-to-Omnetics adaptor (Neuralynx) and connected to a unity gain 18-channel headstage tethered to a preamplifier [ $2 \times$ gain; $0.15 \mathrm{kHz}$ (high-pass), $8 \mathrm{kHz}$ (lowpass); Plexon]. Sixteen channels of raw data were digitized by a Multichannel Acquisition Processor (MAP) and visualized using Sort Client (Plexon). Tetrodes were advanced by turning a drive screw (one full turn, $250 \mu \mathrm{m})$ coupled to each tetrode and were advanced in one-quarter-turn $(62.5 \mu \mathrm{m})$ increments with the distance recorded to aid in localization of units (Richardson et al., 2013b, their Fig. 1). To avoid unit resampling, after all units on a tetrode were studied that tetrode was advanced at least $125 \mu \mathrm{m}$. When auditory responsive units/field potentials were no longer present, tetrodes were left in position for marking.

Similar to Richardson et al. (2013b), spikes determined to be from single units were sorted using standard methods (amplitude threshold and principal component analysis) and saved as timestamps. Timestamps were relayed to a system running a custom program Auditory Neurophysiology Experiment Control Software (ANECS; Ken Hancock, Blue Hills Scientific) for stimulus generation and real-time analysis of unit responses. During the recording period, the experimenter took precautions to ensure that the animal was not asleep. Whenever there was an unexpected change in the firing rates of a single unit under investigation, data collection was paused and the booth door was opened to make sure the animal was awake and alert. As noted above, animals were kept on a reverse day/night cycle so their active period was during the recording sessions.

When recordings were complete ( $1-4$ weeks), rats were anesthetized with ketamine and xylazine as described above and current pulses ( $5 \mu \mathrm{A}$ for $5 \mathrm{~s}$ ) were passed through the tip of each tetrode wire, producing a small lesion. Rats were cardiac perfused with PBS $(0.1 \mathrm{M}), \mathrm{pH} 7.4$, followed by parafor- maldehyde (4\%), and brains were removed, placed in paraformaldehyde (1-2 h), and then transferred to sucrose (20\%). Frozen coronal sections (30-35 $\mu \mathrm{m}$ thick) were stained with fast thionin. Electrode tracks were used to determine the position of each recording site relative to the final location of the tetrode tip (Paxinos and Watson, 1998).

Awake recordings and attention. As detailed by Richardson et al. (2013b) and Kalappa et al. (2014), animals were placed in a darkened acoustic chamber under gentle orienting restraint (they could turn around but were pretrained not to do so) with only SAM stimuli to listen to. There was no other known distractors to divide their attention so the rat's sole activity was to attend to environmental sounds, which were the SAM stimuli presented from the speaker located above their heads. This simple task, from an attentional point of view, would not be expected to place an attentional demand on aged animals.

Anesthetized preparation. Initial anesthesia for surgery were the same as described for the awake preparation. Anesthesia was then maintained with intraperitoneal injections of $100 \%$ urethane (initially $1.3 \mathrm{ml} / \mathrm{kg}$, then booster doses at one-third of the initial dose; Sigma-Aldrich), with the aged booster dose reduced by $\sim 20 \%$ (Cai et al., 2014; Cai and Caspary, 2015). Rats were placed in a modified stereotaxic frame in a sound-attenuating booth (Industrial Acoustic) with body temperature maintained at $37 \pm 0.5^{\circ} \mathrm{C}$ by a thermostatically controlled heating blanket. The skull surface and left occipitoparietal cortex, dorsal to the MGB, were exposed. A tungsten or a carbon fiber electrode was gradually advanced into the MGB by a piezoelectric advancer (David Kopf Instruments). The electrodes were coupled to a headstage preamplifier and a PC running MAP software and Sort Client (Plexon) for real-time spike sorting.

SAM stimuli paradigms and single-unit recording procedures. Stimulus paradigms and single-unit sorting/recording procedures were the same in both awake and anesthetized preparations. Acoustic signals were generated using a 16-bit digital-to-analog converter (TDT RX6, Tucker Davis Technologies), amplified (P2500S, Yamaha), and transduced by a tweeter (model FT17H, Fostex) placed $30 \mathrm{~cm}$ above animal's head. The Fostex tweeter was calibrated off-line using a one-quarter inch microphone (model 4938, Brüel \& Kjær) placed at the approximate location of the rat's head. Calibration tables in decibel sound pressure level (SPL) were used to set programmable attenuators (TDT PA5, Tucker Davis Technologies) to achieve pure tone levels accurate to within $2 \mathrm{~dB}$ SPL for frequencies $\leq 45 \mathrm{kHz}$. Response maps were used to determine the characteristic frequency (CF) of sorted single units (Cai and Caspary, 2015). Random tone-burst stimuli (50 ms duration, $4 \mathrm{~ms}$ rise/fall time, $2 \mathrm{~Hz}$ rate) were presented in $0.10-0.25$ octave frequency steps $(1-42 \mathrm{kHz})$ in $10 \mathrm{~dB}$ SPL steps $(0-80 \mathrm{~dB})$ to determine the response maps. Real-time 

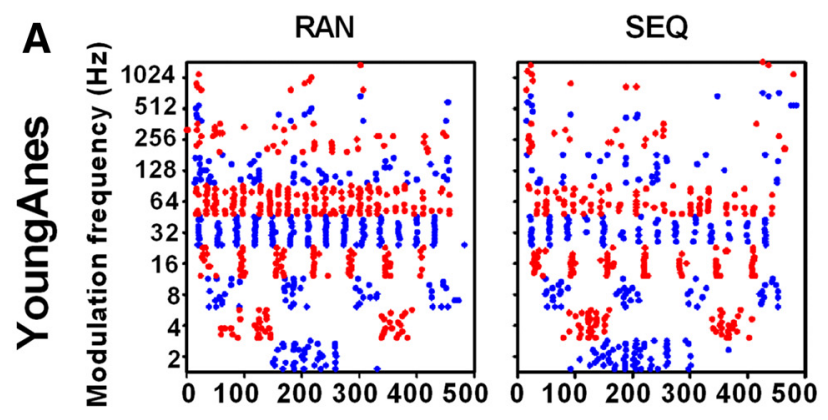

B

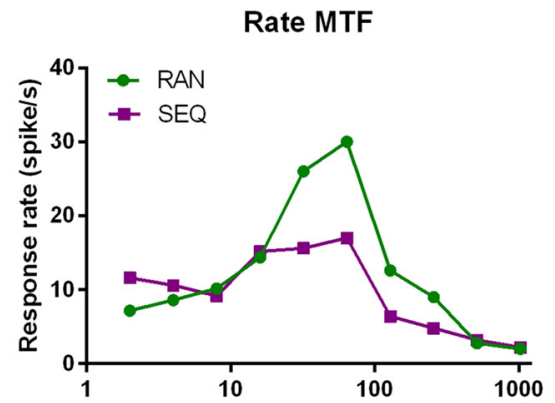

\section{$c$}
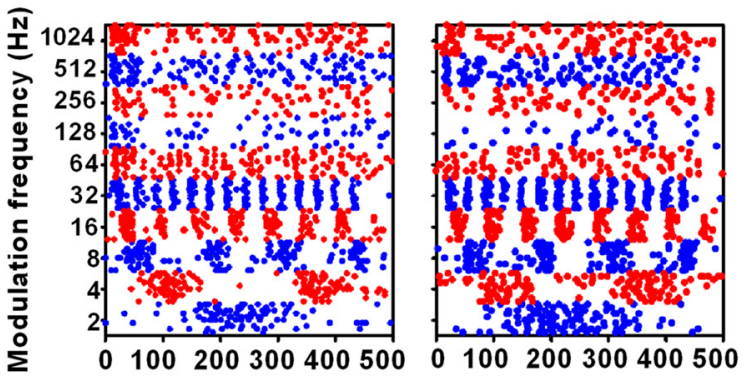

D
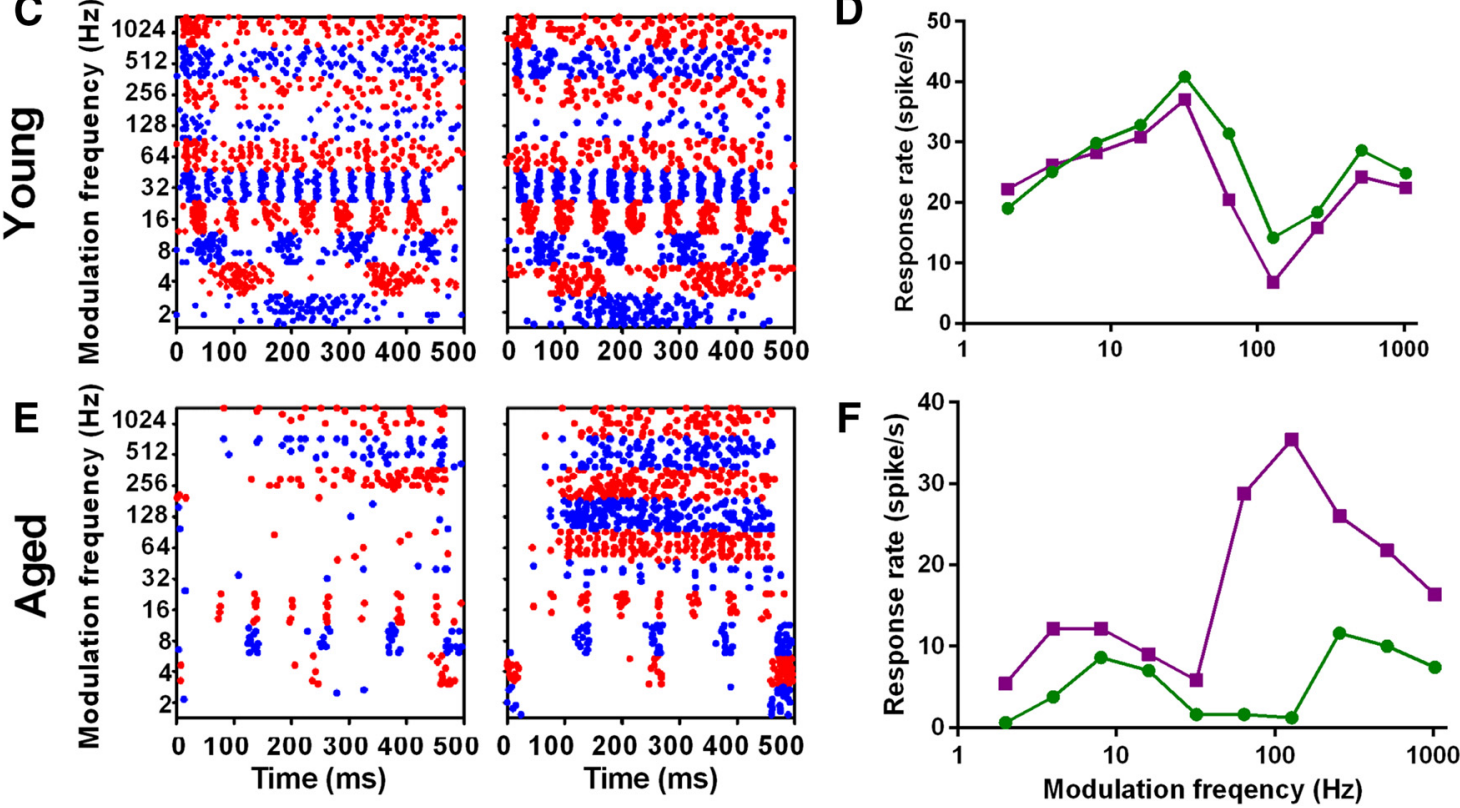

Figure 3. Representative units from each sequence preference category. $\boldsymbol{A}-\boldsymbol{F}$, Dot rasters and rMTFs from exemplar MGB units from the three rat groups/conditions in response to SAM stimuli with fms presented randomly or sequentially. $A, B, A$ bandpass unit from a young anesthetized rat showed enhanced responses to randomly presented fms (RAN $>$ SEQ). Enhanced RAN responses were greatest at or near rBMF. C, $\boldsymbol{D}$, A mixed unit from young awake rats showed a light preference for RAN SAM (RAN $=S E Q)$. $E, F, A$ mixed unit from an aged awake rat MGB showed preferential responses to sequentially presented SAM stimuli (RAN < SEQ). Responses to SEQ SAM were increased at all fms compared with responses to RAN stimuli, with largest response differences at higher fms.

single-unit activity was sampled at $100 \mathrm{kHz}$ using ANECS and archived for off-line analysis.

SAM carrier frequency was set at the unit's CF or broadband noise (BBN); rate modulation transfer functions (rMTFs) and temporal modulation transfer functions (tMTFs) were determined for each unit at 30 $\mathrm{dB}$ above $\mathrm{CF}$ threshold in response to 2/s, 450-ms-long SAM stimuli (4 ms rise-fall time, 100\% depth) with fms stepped between 2 and $1024 \mathrm{~Hz}$. Spikes were collected over a $500 \mathrm{~ms}$ period, following stimulus onset for 10 or 16 stimulus repetitions at each envelope frequency. SAM stimuli were presented as two separate sets, either with $\mathrm{fms}$ presented at random/ interleaved or with fms repeated and stepped in increasing sequential order (see Fig. 2).

Data analysis. Responses were analyzed off-line. MTFs were determined using spike rate (rMTF) and temporal synchronization (tMTF) measurement at each $\mathrm{fm}$ tested.

Sequence preference ratio was calculated based on total responses to all the frequencies of SEQ or RAN SAM, with a ratio of RAN-preferring unit $<0.95$ and SEQ preferring unit $>1.05$. Ratios between the range of 0.95 and 1.05 were considered nonselective units (see Fig. 4).

A sequence-preferring index (SPI) was calculated using the following equation: $\mathrm{SPI}=\left[\left(\mathrm{AUC}_{\mathrm{RAN}}-\mathrm{AUC}_{\mathrm{SEQ}}\right) /\left(\mathrm{AUC}_{\mathrm{RAN}}+\mathrm{AUC}_{\mathrm{SEQ}}\right)\right]$, modified from the novelty response index (Lumani and Zhang, 2010); and the area under successive frequency segments of the rMTF curve (AUC) values were based on the rMTF curve calculated using Matlab (MathWorks). The range of SPI values varied between -1 and +1 , with -1 representing a complete SEQ-preferring response, and + 1 represent- ing a complete RAN-preferring response (see Fig. 6). Statistical analysis was performed using GraphPad Prism 6. All values are expressed as means \pm SEM. ${ }^{\star} p<0.05,{ }^{* *} p<0.01,{ }^{* * *} p<0.001$, and ${ }^{* * *} p<0.0001$ were treated as statistical significance level.

Phase-locking ability was evaluated by standard vector strength (VS) equation as follows: $V S=\left(\frac{1}{n}\right) * \sqrt{\left(\sum \cos \varphi i\right)^{2}+\left(\sum \sin \varphi i\right)^{2}}$, where $n=$ total number of spikes and $\varphi i=$ phase of observed spike relative to fm. (Goldberg and Brown, 1969; Yin et al., 2011). Statistical significance was assessed using the Rayleigh statistic, to account for differences in the number of driven spikes, with a Rayleigh statistic value $>13.8$ considered to be statistically significant (Mardia and Jupp, 2000; see Fig. 7).

Unit response profiles were parsed into bandpass (Fig. $3 B$ ), mixed (Fig. $3 D, E$ ), or high-pass, based on the shape of their rMTFs across fms, similar to studies by Bartlett and Wang $(2007,2011)$ and Cai et al. $(2014,2015)$. Bandpass units were those units with strong selectivity for a narrow subset of $f \mathrm{~ms}$, therefore showing a single peaked rMTF. The peak of the rMTF was defined as rate best $f m$ (rBMF). High-pass response types included units showing increasing rate responses as $\mathrm{fm}$ increased. The most prevalent response type in the present study was the mixed type, which results in units with rMTFs having peaks separated by a fixed minimum, which divides the rMTF into a lower (bandpass) and a higher (high-pass) fm section. Units classified as "atypical" types responded equally to different fms with no fm selectivity seen in their rMTF. 


\section{Results}

The present study recorded 133 carefully isolated units from the MGBs of unanesthetized animals using advanceable tetrode microwires; 73 units from 13 young (4-6 months old) and 60 units from 11 aged (28-30 months old) rats. Another 42 units from the MGBs of nine young (4-6 months old) anesthetized rats were included for group comparison. In addition, to confirm the effects of anesthesia, we recorded 16 units from the MGBs of two aged (28-30 months old) anesthetized rats.

All units in the study were recorded within the auditory thalamus (dorsal, ventral, or medial subdivisions). Based on the present data, no significant differences were found between the different subdivisions. Ninety-five percent of units were easily discriminated and classified as single units. The remaining five percent were from small clusters of two or three unsorted units. Cluster data findings were consistent with the single-unit findings. rMTFs and tMTFs were acquired in response to RAN-presented or SEQpresented SAM stimuli (Fig. 2). To optimize responses for analysis, either a broadband noise carrier or a CF carrier was chosen based on which SAM carrier generated the largest number of total spikes. Since most of the units studied here showed more robust responses to the $\mathrm{BBN}$ carrier, results presented are based on using a BBN SAM carrier unless otherwise stated. A small number of atypical rMTF response types were seen in all experimental groups. There were few rMTF response type differences between the three major groups using the BBN carrier RAN SAM stimuli (Table 1). Although most units showed sequence preference, a majority of units maintained their rMTF response type using either RAN SAM or SEQ SAM stimuli.

\section{Age, anesthesia, and sequence rate} changes in SAM MGB unit responses We examined whether anesthesia altered
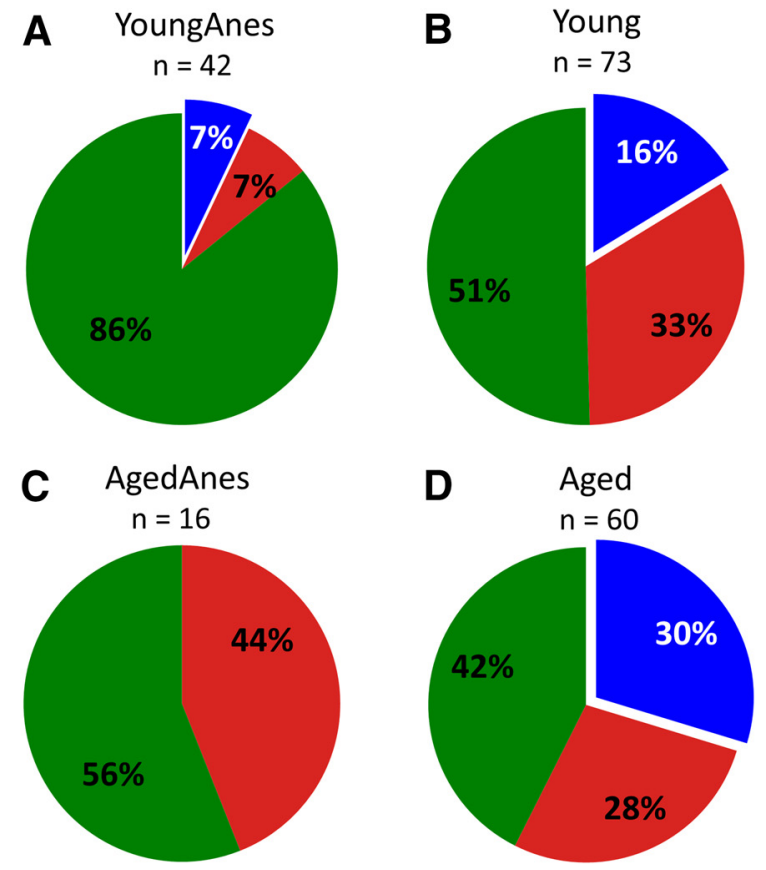

Table 1. rMTF response types to BBN carrier RAN SAM stimuli

\begin{tabular}{lllll}
\hline & Bandpass & Mixed & High-pass & Atypical \\
\hline $\begin{array}{c}\text { Young anesthetized } \\
(n=42)\end{array}$ & $33 \%(n=14)$ & $40 \%(n=17)$ & $17 \%(n=7)^{* * * *}$ & $10 \%(n=4)$ \\
$\begin{array}{c}\text { Young awake } \\
(n=73)\end{array}$ & $37 \%(n=27)$ & $48 \%(n=35)$ & $4 \%(n=3)$ & $11 \%(n=8)$ \\
$\begin{array}{c}\text { Aged awake } \\
(n=60)\end{array}$ & $25 \%(n=15)$ & $50 \%(n=30)$ & $5 \%(n=3)$ & $20 \%(n=12)^{*}$ \\
\hline
\end{tabular}

Bandpass and mixed MGB units were major SAM response types for all three groups. Of the three groups, MGB units from young anesthetized rats showed the largest percentage of high-pass SAM response type ${ }^{* * *} p<$ $0.001, x_{(3)}^{2}=22.85, \chi^{2}$ test). The percentage of atypical SAM response types increased as rats became older $\left({ }^{*} p<0.05, x_{(3)}^{2}=8.048 ; \chi^{2}\right.$ test $)$.

Figure 4. Comparison of response ratio among four groups. $A-D$, Percentages of MGB units showing response ratios (SEQ/RAN) to SAM stimuli set in young anesthetized ( $\boldsymbol{A}$, YoungAnes), young awake ( $\boldsymbol{B}$, Young), aged anesthetized ( $\boldsymbol{C}$, AgedAnes), and aged awake ( $\boldsymbol{D}$, Aged) rats. The percentage of units showing a preference for SEQ SAM stimuli increased from young anesthetized rats (7\%, 3 of 42 ) to young awake rats (16\%, 12 of 73 ) and then aged awake rats (30\%, 18 of 60$)$. Aged awake rats showed the highest percentage of SEQ-preferring units, while none of the units from aged anesthetized rats shows SEQ preference. $\chi^{2}$ Test indicates significant portion differences $\left(x_{(2)}^{2}=\right.$ $25.15, p<0.0001$ ) between the anesthetized group (YoungAnes) and unaesthetized group (Young). There was a significant, $p<0.05$ $\left(x_{(2)}^{2}=8.934, \chi^{2}\right.$ test $)$ difference between young and aged awake groups. the preference for RAN or SEQ SAM stimuli in MGB units of unanesthetized and anesthetized rats, as reflected in exemplar dotraster and rMTFs. Figure 3 suggests significant differences in exemplar rMTF response types between the three major groups in response to RAN or SEQ SAM stimuli from MGB unit recordings. Recordings from MGB units in young anesthetized rats typically showed strong preferences for RAN SAM stimuli, which significantly contrasted with recordings from young awake and aged awake MGB units $\left(x_{(2)}^{2}=8.934, p<0.05, \chi^{2}\right.$ test; Figs. 3, 4). For additional confirmation regarding the impact of anesthesia, units were recorded from the MGB of two aged anesthetized animals. No aged MGB units from anesthetized rats preferred sequential stimuli. Nine units were RAN preferring and seven units showed no SAM sequence preference.

There were significant age-related sequence preference changes between SAM responses when comparing rMTFs from awake young and aged animals $\left(x_{(2)}^{2}=8.934, p<0.05, \chi^{2}\right.$ test; Fig. 4). When total spike ratio obtained from rMTFs in response to SEQ and RAN SAM stimuli, units were parsed into RAN-preferring, SEQ- preferring, or equal/no preference responses to SAM stimuli (Fig. $4 A-D)$, RAN preferring was the largest category from all groups. However, there was a significant age-related increase that nearly doubled the percentage of aged MGB units preferring SEQ SAM stimuli in awake rats (Fig. 4D).

\section{Group rMTF sequence differences within and across fms}

When examining the trial-by-trial responses, we found the enhancement to SEQ SAM stimuli for units from aged animals occurred with increasing $\mathrm{fms}$ over repeated trials within one $\mathrm{fm}$, especially at higher fms. A typical SEQ-preferring unit from an aged awake animal showed a clear tendency to increase its responses from the first to the 16th trial of the repeating $512 \mathrm{~Hz} \mathrm{fm}$ SAM stimulus (Fig. $5 A$ ). In contrast to the unit from aged awake MGB (Fig. 5A), units from young anesthetized rats were overwhelmingly RAN preferring. Figure $5 B$ shows a typical unit response from an anesthetized rat MGB to a repeating $512 \mathrm{~Hz} \mathrm{fm}$ SAM stimulus. Initial large responses were followed by rapid adaptation, until few responses remain at later stimulus trials. A 
A
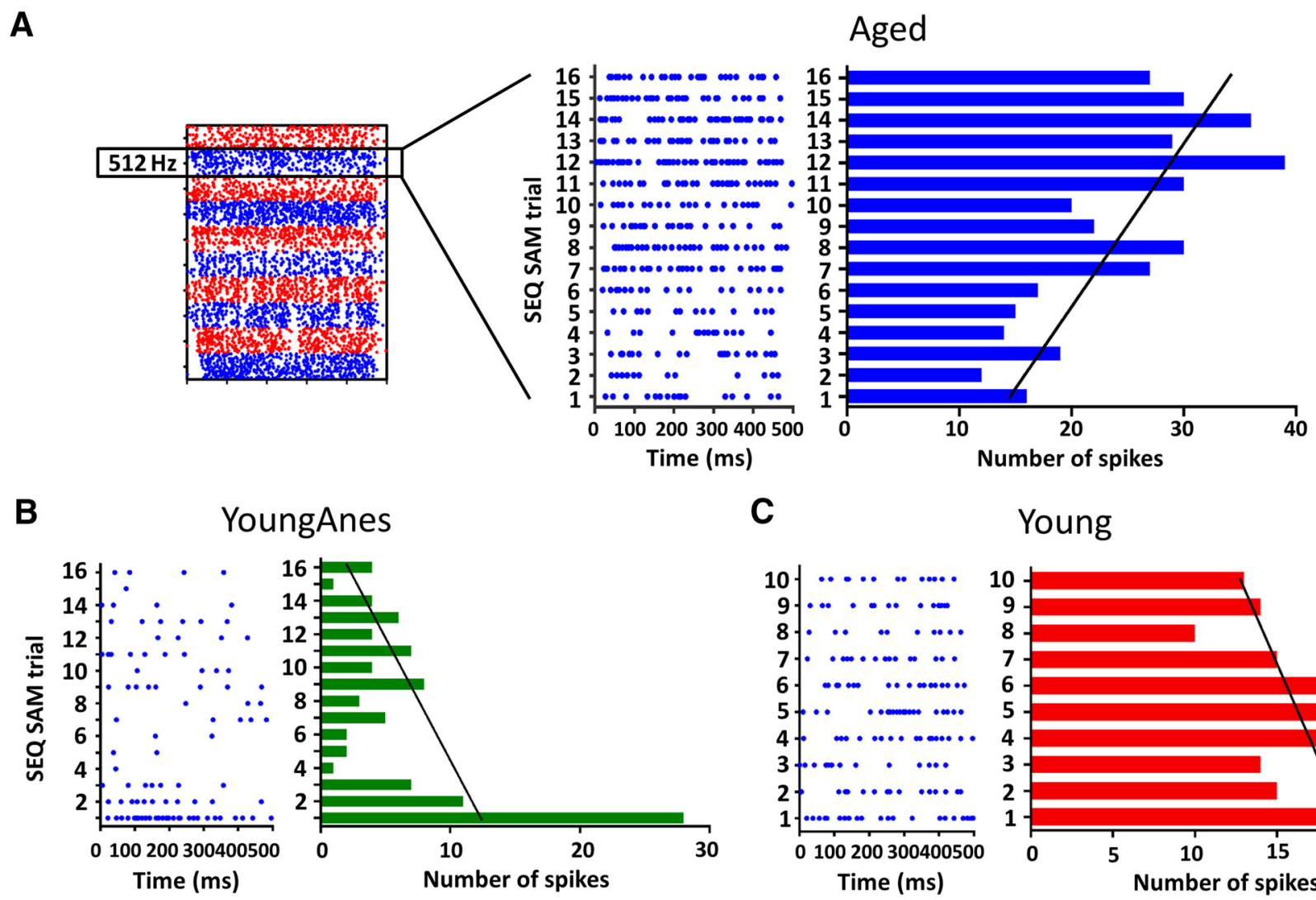

C

Young

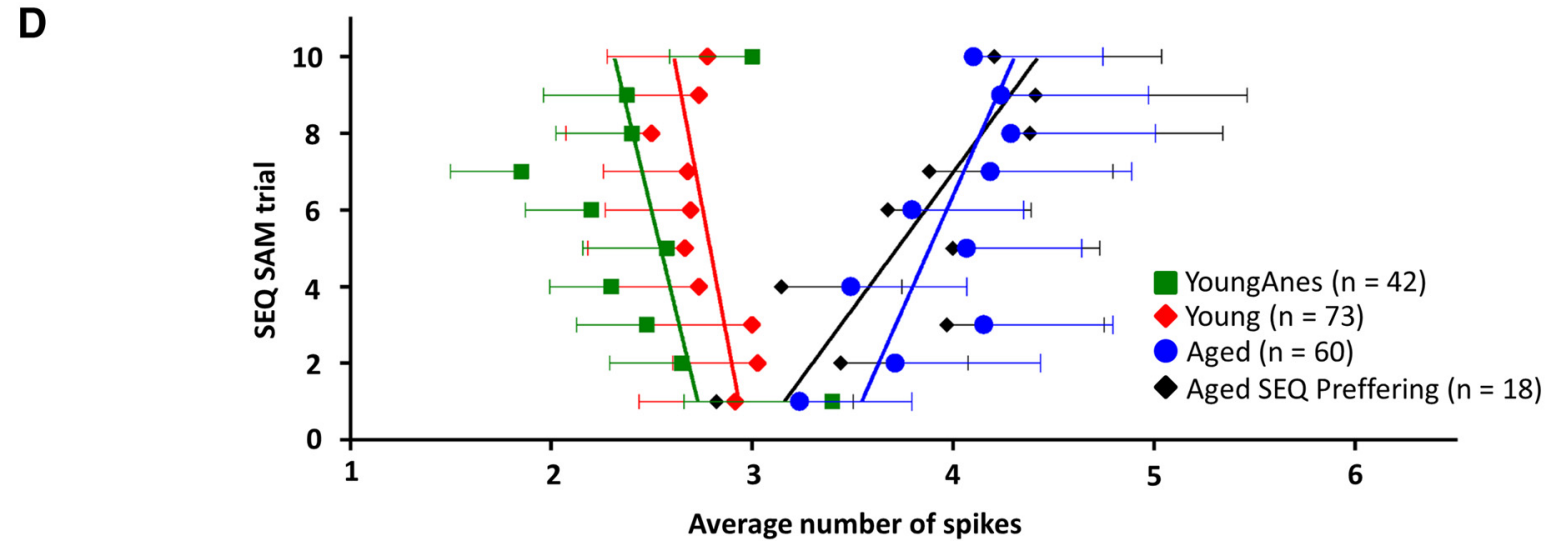

Figure 5. Trial-by-trial response analysis to SEQ SAM presentation at $512 \mathrm{~Hz}$. A-C, A trial-by-trial slice of responses to 10 or 16 repeating presentations of a $512 \mathrm{~Hz}$ SEQ SAM stimuli from one MGB unit of aged awake rat ( $\boldsymbol{A}, \mathbf{A g e d})$, one from young anesthetized rat ( $\boldsymbol{B}$, YoungAnes), and one from young awake rat ( $\boldsymbol{C}$, Young). $\boldsymbol{A}$, Identical $512 \mathrm{~Hz}$ fm trials were presented showing a gradual increase in the number of spikes/trial, i.e., enhanced responses to repeated $512 \mathrm{~Hz}$ stimuli from the aged awake rat MGB unit. $\boldsymbol{B}, \mathrm{A}$ typical unit from a young anesthetized rat shows a decreasing spikes/trial with increasing repetition of the $512 \mathrm{~Hz}$ fm slice. Units from MGBs in anesthetized rats showed rapid adaptation to identically repeated SAM trials. C, Units from the young awake group showed slow adaptation to repeated identical stimuli trials. $D$, Group data (mean \pm SE) showed statistically different trend line slopes when plotting average spikes against each $512 \mathrm{~Hz} f \mathrm{~m}$ SEQ SAM trial between aged awake (Aged) and young anesthetized (YoungAnes) groups (ANCOVA, 2-tailed, $p<0.05$ ); and between Aged and unaesthetized (Young) groups (ANCOVA, 2-tailed, $p<0.01$ ). The slope of the trend line for the 18 SEQ-preferring MGB units from the Aged group shows slightly steeper adaptive response when compared with all 60 aged MGB units.

sample unit from the young awake group showed some degree of adaptation to SEQ SAM trials at $512 \mathrm{~Hz}$, but not the magnitude of adaptation as the exemplar from the young anesthetized group (Fig. 5C). Average trial responses to $512 \mathrm{~Hz} f \mathrm{~m}$ SEQ SAM for all units in each group were compared (Fig. $5 D$ ). Similar to the examples in Figure $5 A-C$, group results from aged MGBs showed enhanced responses across SEQ presentation at $512 \mathrm{~Hz} \mathrm{fm}$. The rate of adaptation to SEQ SAM at $512 \mathrm{~Hz}$ fm for each group was greatest for units from anesthetized MGBs, with units from young awake rats showing adaptation rates between units from young anesthetized and aged awake MGB units (Fig. 5D). There were significant differences between the adaptation slopes of the group trend lines (aged awake vs young anesthetized, $p<0.05$; aged awake vs young awake, $p<0.01$, ANCOVA, two tailed). When the response to repeated $512 \mathrm{~Hz}$ SAM trials from the 18 SEQ-preferring aged units were plotted separately from the total aged group, the slope of the linear fit for this subset of units was indeed larger in comparison to the slope of the fit for all unit responses recorded from awake aged MGBs, but this difference was not significant (Fig. 5D, black line). 

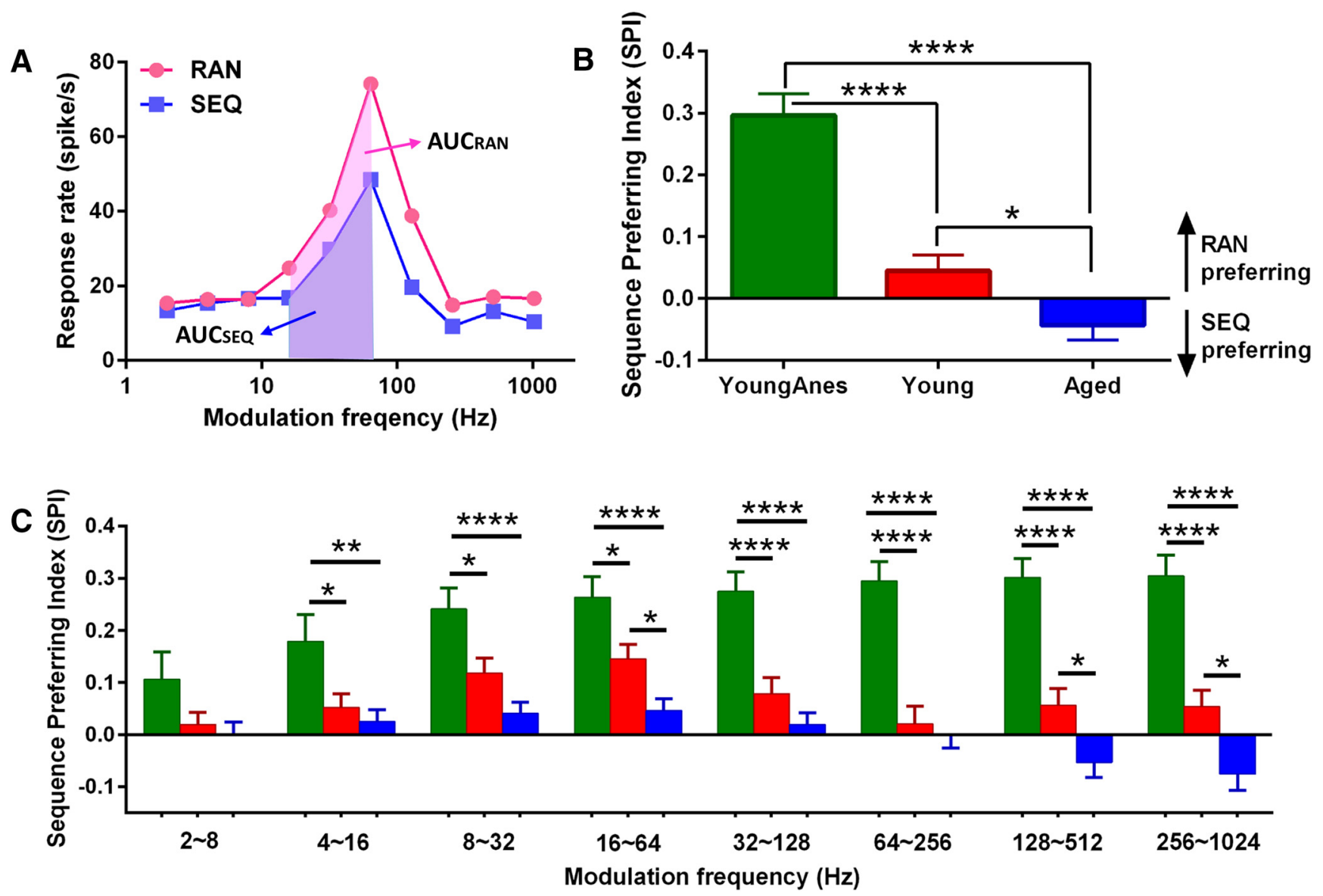

Figure 6. Sequence preference index (SPI) for all groups. A, Based on the rMTF curve, total AUC and AUC for three consecutive fms were calculated. AUCs for each unit were evaluated for sequentially ( $\mathrm{AUC}_{\mathrm{SEQ}^{\prime}}$ blue shadow) and randomly (AUC $\mathrm{RAN}_{\text {, }}$, pink shadow) presented SAM stimuli. $\boldsymbol{B}$, Total SPIs indicated a significant difference between anesthetized (YoungAnes) and unanaesthetized awake (Young and Aged) rats. There was a significant difference between young and aged awake groups. C, SPIs of anesthetized rat units showed significant differences across most $f m$ ranges compared with the two awake age-group MGB units. There was a significant age-related change between the two awake groups, with young rats showing a significantly larger SPI (stronger RAN preferring) at $16 \sim 64 \mathrm{~Hz}$ and for fms above $128 \mathrm{~Hz}$. All data were presented as mean $\pm \mathrm{SE}$; statistical analysis were performed using ANOVA with post hoc Tukey's correction by Graphpad. ${ }^{*} p<0.05,{ }^{* *} p<0.01$, ${ }^{* * *} p<0.0001$.

To compare responses between RAN and SEQ stimuli across fms, we used the area under successive frequency segments of the rMTF curve (AUC). To quantify differences between groups, we used an SPI (Fig. 6A). For the two unanesthetized groups, the total SPI value for units recorded from young awake MGBs showed larger AUC values for responses to RAN SAM stimuli (positive SPI; SPI, $0.045 \pm 0.026$ ); while aged awake MGB units showed larger AUC values for SEQ SAM stimuli (negative SPI; SPI, $-0.043 \pm 0.024$; Fig. $6 B$ ). Units recorded from young and aged awake groups showed significant age-related differences $\left(F_{(2,172)}=33.26, p<0.05\right.$, one-way ANOVA with post hoc Tukey's correction). Notably, units recorded from young anesthetized MGBs were significantly different $\left(F_{(2,172)}=33.26, p<\right.$ 0.0001, one-way ANOVA with post hoc Tukey's correction) from either the young or aged awake units and showed the highest positive SPI values (SPI, $0.296 \pm 0.035$; Fig. $6 B$ ), indicating strong RAN preference. Nine of $16 \mathrm{MGB}$ units from anesthetized aged rats showed a RAN preference and had SPI values similar to those of the young anesthetized group (SPI, $0.285 \pm 0.049$ ).

To determine whether specific SEQ versus RAN SAM preferences existed for certain $\mathrm{fm}$ ranges, SPI values for three consecutive $\mathrm{fm}$ combinations were calculated separately as shown in Figure $6 A, C$. SPI values for units recorded from young MGB units (anesthetized and awake) were all positive, indicating a preference for RAN SAM stimuli across all the fm segments. In contrast, units recorded from aged awake MGB units showed negative SPI at $f m s ~ \geq 128 \mathrm{~Hz}$ (high $\mathrm{fm}$ ranges; Fig. $6 \mathrm{C}$ ). These data suggest an age-related shift from RAN to SEQ SAM stimuli preference, with significant differences between units from aged awake rats and units from young anesthetized/awake rats at the $128 \sim 512 \mathrm{~Hz}$ range $\left(F_{(2,172)}=25.55, p<0.0001 / p<0.05\right.$, oneway ANOVA with post hoc Tukey's correction) and 256 1024 Hz range $\left(F_{(2,159)}=26.57, p<0.0001 / p<0.05\right.$, one-way ANOVA with post hoc Tukey's correction). For $\mathrm{fm}$ ranges $<128 \mathrm{~Hz}$, SPI values from aged units were smaller than those from the young rats, suggesting an age-related loss of sequence selectivity (decreased ability to follow the RAN SAM stimuli) at low $\mathrm{fms}$. These differences were statistically significant at the $16-64 \mathrm{~Hz} \mathrm{fm}$ range $\left(F_{(2,172)}=11.82, p<0.05\right.$, one-way ANOVA with post hoc Tukey's correction), a range of frequencies normally showing the highest phase-locking for rat MGB units (Cai et al., 2014). SPI values from young anesthetized rat MGBs showed dramatic differences compared with unanesthetized groups (both young and aged) for all but the lowest $f m$ ranges $\left(F_{(2,172)}=33.26, p<0.01\right.$ or $p<0.0001$, one-way ANOVA with post hoc Tukey's correction).

Similar analyses were conducted with RAN versus SEQ responses to SAM stimuli using a CF carrier. With a CF carrier, significant differences in the SPI for all $\mathrm{fm}$ ranges combined were 
A

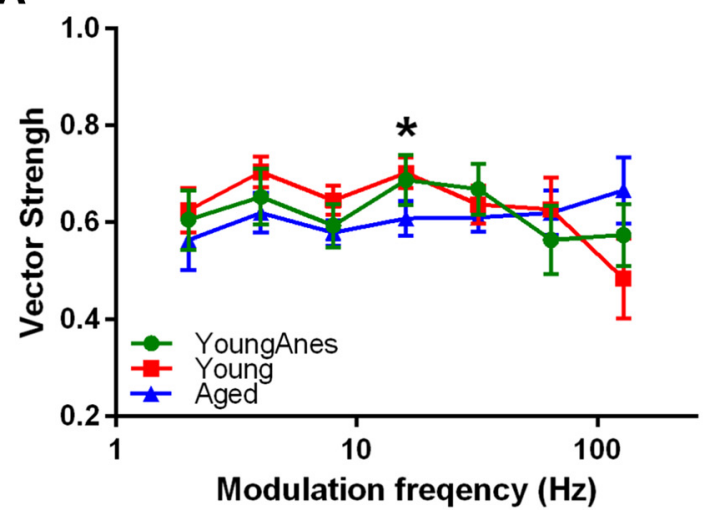

B

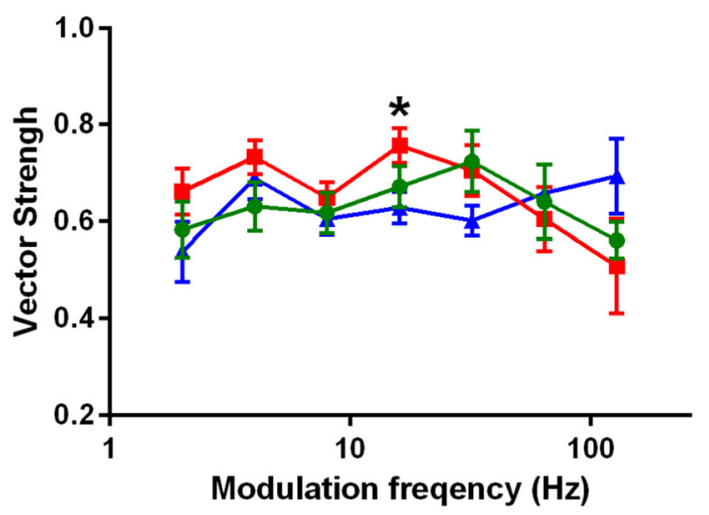

Figure 7. RAN and SEQ SAM stimuli presentation does not alter temporal coding fidelity. $\boldsymbol{A}, \boldsymbol{B}$, Average VS values at each fm are plotted for all three groups when stimuli were presented as RAN (A) or SEQ (B). Significant age-related changes were detected at $16 \mathrm{~Hz}$ fm for responses to both RAN and SEQ SAM stimuli between unaesthetized (Young) and aged awake (Aged) groups. All data were presented as mean $\pm \mathrm{SE}$; statistical analysis were ANOVA with post hoc Tukey's correction using Graphpad. * $p<0.05$.

observed between the young anesthetized conditions compared with MGB units from the two awake groups $(p<0.01$, one-way ANOVA with post hoc Tukey's correction). However, while the age-related SPI changes for all $\mathrm{fm}$ ranges combined were less than those from MGB units in young rats, this did not reach significance ( $p=0.054$, one-way ANOVA with post hoc Tukey's correction). Age-related RAN versus SEQ SAM unit coding differences were significant at the highest $f m$ ranges $(256 \sim 1024$ $\mathrm{Hz}$ ) using a CF carrier $(p<0.05$, one-way ANOVA with host-hoc Tukey's correction).

\section{Group tMTF sequence differences across fms}

To determine the impact of SEQ and RAN presentation on phase-locking ability, VS values for fms between 2 and $128 \mathrm{~Hz}$ were calculated and compared between groups. In response to RAN SAM stimuli, units from young awake rats displayed relatively high, stable VS values between 0.62 and $\sim 0.71$ for most fms tested, with lower values at the highest fms (Fig. $7 A$ ). VS from aged MGB units ranged between 0.57 and $\sim 0.66$ across fms (Fig. $7 A$ ). When responding to RAN SAM, there were significant agerelated VS differences between awake groups at $16 \mathrm{~Hz}\left(F_{(2,83)}=\right.$ $3.912, p<0.05$, one-way ANOVA with post hoc Tukey's correction). When responding to SEQ SAM, a significant difference $\left(F_{(2,83)}=3.756, p<0.05\right.$, one-way ANOVA with post hoc Tukey's correction) was seen at $16 \mathrm{~Hz}$ when young awake and aged awake rat units were compared (Fig. $7 B$ ).

\section{Discussion}

\section{Summary}

Significant age-related and anesthetic-related differences were found in MGB unit responses to RAN-presented versus SEQpresented SAM stimuli. Single units from anesthetized MGBs showed an enhanced preference for RAN SAM stimuli. This preference was significantly greater than the RAN preferences shown in recordings from young and aged unanesthetized MGB units. There was a significant age-related preference for SEQ SAM stimuli especially at higher $\mathrm{fms}(>128 \mathrm{~Hz})$. In higher auditory structures, including the MGB, rMTFs are most reflective of changes at higher fms, while tMTFs are most sensitive/reflective to lower fms (Bartlett and Wang, 2007; Rabang and Bartlett, 2011). The present findings suggest that age-related sequence preference is selectively revealed at higher fms in rMTFs. The lack of age-related sequence preference changes in tMTFs would be consistent with the primary age-related findings being at higher fms. Taken together, rate modulation data found significant age-related changes at higher fms, with aged MGB units showing a notable switch from RAN to SEQ preferring (larger negative SPI value) when responding to SAM stimuli. A modest age-related decrease in temporal locking (smaller VS) was detected at low/middle fms.

\section{Changes of bottom-up processing with aging}

Aged rodents exhibit a number of age-related changes which negatively impact the veracity of the ascending acoustic message. Peripheral auditory changes include a sloping low-frequency loss of outer hair cells and a small loss of apical and basal inner hair cells (for review, see Willott et al., 1991; Saitoh et al., 1994; Gratton et al., 1996, 1997; Spongr et al., 1997; Ingham et al., 1999; Turner et al., 2005; Tang et al., 2014) accompanied by auditory nerve fiber loss (Keithley et al., 1989, 1992; Dazert et al., 1996; Schmiedt et al., 1996). Parallel central aging effects include a net down-regulation of glycinergic and GABAergic inhibition in the cochlear nucleus (Banay-Schwartz et al., 1989b; Krenning et al., 1998; Caspary et al., 2002), inferior colliculus (Banay-Schwartz et al., 1989a,b; Caspary et al., 1990; Gutierrez et al., 1994; Milbrandt et al., 1994, 1996; Raza et al., 1994), MGB (Richardson et al., 2013a), and auditory cortex (Ling et al., 2005; Caspary et al., 2013; Stebbings et al., 2016). This CANS loss of inhibition at least partially subserves the age-related loss of accurate temporal processing seen in older humans (Harris et al., 2012; Mattys and Scharenborg, 2014). Units recorded from rodent models of aging show altered response properties, including increased discharge rates at higher intensities within the excitatory response area and less precise temporal processing of modulated sounds (Palombi and Caspary, 1996a,b,c; Mendelson and Ricketts, 2001; Shaddock Palombi et al., 2001; Lee et al., 2002; Walton et al., 2002; Mendelson and Lui, 2004; Caspary et al., 2005; Parthasarathy et al., 2016).

\section{Effects of top-down modulation with anesthesia and aging} Incoming auditory information is constantly being monitored and sound perception is a balance between filtering repetitive signals and identifying different/novel salient signals using either upstream brainstem automatic processes or more cognitively based downstream mechanisms (Skoe and Kraus, 2010; Skoe et al., 2014; Malmierca et al., 2015). Signals difficult to identify initiate cognitive and attentional processes that alter the bottom-up/ 
top-down balance. We suggest that the present findings reflect these changes. Anesthesia is thought to profoundly decrease topdown influences (Aberg et al., 2009; Jordan et al., 2013; Mashour, 2014). The present study finds that responses from young MGB units in anesthetized animals reflect increased bottom-up processing with repeated signals. This induces strong adaptation in the absence of learning-based/cognitive modulation (Skoe et al., 2014; Malmierca et al., 2015). MGB units recorded from young awake rats show a greater balance between bottom-up, automated adaptation and descending/top-down experience/attentional influences, reflected by a mix of SEQ-preferring and RAN-preferring units. MGB units from aged, awake rats, especially at higher fms, show a clear preference for SEQ-presented SAM signals. This raises the question, "Are aged rats listening to the repeating SAM signal and employing top-down resources to favor the expected next stimulus (Fig. 1)?” This idea is supported by the observed preference of aged MGB units for sequentially presented SAM stimuli, where successive repetitions of the same SAM signal at one $\mathrm{fm}$ showed increasing responses across trials (Fig. 5). Figure 5A,C shows spike-rate histograms that support enhanced top-down involvement in unit responses from the aged rat MGBs as compared with the adapting responses seen from young rat MGB units under anesthesia, which are considered to show weak top-down influences.

\section{Possible mechanisms for preference shifting between anesthesia and aging}

Previous studies using a simple tonal SSA paradigm reported that anesthesia did not significantly alter unit responses to SSA stimuli in the inferior colliculus (Duque and Malmierca, 2015), while SSA studies in awake MGBs found lower novelty/SSA metrics than similar MGB unit studies in anesthetized animals (Anderson et al., 2009; Antunes et al., 2010; Richardson et al., 2013a). The present findings, using a more complex SAM paradigm, found robust anesthesia effects when comparing responses in a sequence-modified SAM stimuli set. As suggested by Malmierca et al. (2015), the complexity of the stimulus likely alters the balance between bottom-up and top-down processing. The $500 \mathrm{~ms}$ SAM stimulus with a BBN carrier used here is more complex than the short pure-tone stimuli used in most SSA studies, and it more closely approximates meaningful vocalizations/language signals. Previous studies in unanesthetized marmosets demonstrated that, as one ascends the CANS, the ability to temporally code/ "lock on" to the envelope of modulated signals decreases with increasing fms and is replaced by an increasingly sparse rate code (Lu et al., 2001; Bartlett and Wang, 2007; Wang et al., 2008; Cai and Caspary, 2015). This temporal processing strategy change in the auditory system from operating on a "moment-by-moment" basis to a "segment-by-segment" basis likely relies heavily on cortical involvement (Lu et al., 2001; Bartlett and Wang, 2007; Wang et al., 2008; Cai and Caspary, 2015). In the present study, when responding to complex SAM stimuli under anesthesia, it is likely that units from MGBs use/inherit a "moment-by-moment" coding strategy from the lower auditory structures because fewer cortical resources are involved. This results in the observed majority of units from anesthetized MGBs showing response preference to RAN SAM and adapting rapidly to SEQ SAM, which is similar to neurons showing pure-tone SSA in the inferior coliculus and MGB. This differed significantly from the MGB units obtained in unanesthetized rats.

Unlike the dominant RAN-preferring condition in anesthetized rats, MGB units show a more balanced mix of RAN and SEQ preferences when awake. As stated above, when top-down ma- nipulations are not suppressed, MGBs might balance a "segmentby-segment" strategy with the "moment-by-moment" strategy used to process temporally rich signals in both young and aged awake rat MGB units. Although having similar unit categories, there is a two-fold increase in the proportion of aged units preferring SEQ SAM compared with young units. The ability of the elderly to maintain speech understanding in the presence of known deficits in processing temporally rich signals, even when hearing loss and upstream jitter are taken into account, is in itself evidence supporting the greater influence of top-down processing of expected or anticipated stimuli (Dubno et al., 1984; Humes et al., 2012). This concept receives additional support from recent work (Skoe et al., 2014) suggesting that the auditory system continuously monitors auditory scenes, simultaneously creating a representation that in turn informs predictions about future incoming acoustic information. This experience-oriented enhancement is a likely feature of top-down processing known to occur in the elderly (Ostroff et al., 2003; Fakhri et al., 2012; Leung et al., 2013). Rodgers and DeWeese (2014) highlighted the importance of top-down mechanisms in extracting clear speech from a cluttered acoustic environment, while Alain et al. (2014) stated that "listening is a skill that depends on additional abilities including attention and memory." Harris et al. (2012; Mattys and Scharenborg, 2014) quantified age-related changes in a temporal gap detection paradigm and found that certain older adults could partially compensate for temporal losses in gap detection using attentional and cognitive resources. Collectively, these studies found that older adults can compensate for declines in processing a degraded ascending acoustic stream through increased use of cognitive resources (experience/expectation) and by focusing their attention on the acoustic stimulus (Kraus et al., 1995; Bertoli et al., 2001; Alain et al., 2004; Bidelman et al., 2014; Lesicko and Llano, 2016). The enhanced top-down modulation suggested by the increased responses to expected sequentially presented SAM stimuli (Fig. 5) is based on previous auditory experience and expectation to compensate for the loss of accurate peripheral and CANS processing. The present findings suggest a neuronal substrate for an age-related increase in cognitively based, top-down processing of temporally complex auditory information in the thalamus.

\section{References}

Aberg KC, Albrecht E, Tartaglia EM, Farron A, Soom P, Herzog MH (2009) Anesthesia prevents auditory perceptual learning. Anesthesiology 111: 1010-1015. CrossRef Medline

Alain C, McDonald KL, Ostroff JM, Schneider B (2004) Aging: a switch from automatic to controlled processing of sounds? Psychol Aging 19: 125-133. Medline

Alain C, Roye A, Salloum C (2014) Effects of age-related hearing loss and background noise on neuromagnetic activity from auditory cortex. Front Syst Neurosci 8:8. CrossRef Medline

Anderson LA, Christianson GB, Linden JF (2009) Stimulus-specific adaptation occurs in the auditory thalamus. J Neurosci 29:7359-7363. CrossRef Medline

Anderson S, Parbery-Clark A, White-Schwoch T, Kraus N (2012) Aging affects neural precision of speech encoding. J Neurosci 32:14156-14164. CrossRef Medline

Antunes FM, Nelken I, Covey E, Malmierca MS (2010) Stimulus-specific adaptation in the auditory thalamus of the anesthetized rat. PLoS One 5:e14071. CrossRef Medline

Ayala YA, Pérez-González D, Malmierca MS (2016) Stimulus-specific adaptation in the inferior colliculus: The role of excitatory, inhibitory and modulatory inputs. Biol Psychol 116:10-22. CrossRef Medline

Bainbridge KE, Wallhagen MI (2014) Hearing loss in an aging American population: extent, impact, and management. Annu Rev Public Health 35:139-152. CrossRef Medline 
Banay-Schwartz M, Lajtha A, Palkovits M (1989a) Changes with aging in the levels of amino acids in rat CNS structural elements. I. Glutamate and related amino acids. Neurochem Res 14:555-562. CrossRef Medline

Banay-Schwartz M, Lajtha A, Palkovits M (1989b) Changes with aging in the levels of amino acids in rat CNS structural elements. II. Taurine and small neutral amino acids. Neurochem Res 14:563-570. CrossRef Medline

Bartlett EL, Wang X (2007) Neural representations of temporally modulated signals in the auditory thalamus of awake primates. J Neurophysiol 97:1005-1017. Medline

Bartlett EL, Wang X (2011) Correlation of neural response properties with auditory thalamus subdivisions in the awake marmoset. J Neurophysiol 105:2647-2667. CrossRef Medline

Bertoli S, Heimberg S, Smurzynski J, Probst R (2001) Mismatch negativity and psychoacoustic measures of gap detection in normally hearing subjects. Psychophysiology 38:334-342. CrossRef Medline

Bidelman GM, Villafuerte JW, Moreno S, Alain C (2014) Age-related changes in the subcortical-cortical encoding and categorical perception of speech. Neurobiol Aging 35:2526-2540. CrossRef Medline

Cai R, Caspary DM (2015) GABAergic inhibition shapes SAM responses in rat auditory thalamus. Neuroscience 299:146-155. CrossRef Medline

Cai R, Kalappa BI, Brozoski TJ, Ling LL, Caspary DM (2014) Is GABA neurotransmission enhanced in auditory thalamus relative to inferior colliculus? J Neurophysiol 111:229-238. CrossRef Medline

Casali AG, Gosseries O, Rosanova M, Boly M, Sarasso S, Casali KR, Casarotto S, Bruno MA, Laureys S, Tononi G, Massimini M (2013) A theoretically based index of consciousness independent of sensory processing and behavior. Sci Transl Med 5:198ra105. CrossRef Medline

Caspary DM, Raza A, Lawhorn Armour BA, Pippin J, Arnerić SP (1990) Immunocytochemical and neurochemical evidence for age-related loss of GABA in the inferior colliculus: implications for neural presbycusis. J Neurosci 10:2363-2372. Medline

Caspary DM, Palombi PS, Hughes LF (2002) GABAergic inputs shape responses to amplitude modulated stimuli in the inferior colliculus. Hear Res 168:163-173. CrossRef Medline

Caspary DM, Schatteman TA, Hughes LF (2005) Age-related changes in the inhibitory response properties of dorsal cochlear nucleus output neurons: role of inhibitory inputs. J Neurosci 25:10952-10959. CrossRef Medline

Caspary DM, Ling L, Turner JG, Hughes LF (2008) Inhibitory neurotransmission, plasticity and aging in the mammalian central auditory system. J Exp Biol 211:1781-1791. CrossRef Medline

Caspary DM, Hughes LF, Ling LL (2013) Age-related GABAA receptor changes in rat auditory cortex. Neurobiol Aging 34:1486-1496. CrossRef Medline

Dazert S, Feldman ML, Keithley EM (1996) Cochlear spiral ganglion cell degeneration in wild-caught mice as a function of age. Hear Res 100:101106. CrossRef Medline

Dubno JR, Dirks DD, Morgan DE (1984) Effects of age and mild hearing loss on speech recognition in noise. J Acoust Soc Am 76:87-96. CrossRef Medline

Duque D, Malmierca MS (2015) Stimulus-specific adaptation in the inferior colliculus of the mouse: anesthesia and spontaneous activity effects. Brain Struct Funct 220:3385-3398. CrossRef Medline

Fakhri M, Sikaroodi H, Maleki F, Ali Oghabian M, Ghanaati H (2012) Agerelated frontal hyperactivation observed across different working memory tasks: an fMRI study. Behav Neurol 25:351-361. CrossRef Medline

Ferrarelli F, Massimini M, Sarasso S, Casali A, Riedner BA, Angelini G, Tononi G, Pearce RA (2010) Breakdown in cortical effective connectivity during midazolam-induced loss of consciousness. Proc Natl Acad Sci U S A 107:2681-2686. CrossRef Medline

Fitzgibbons PJ, Gordon-Salant S (1994) Age effects on measures of auditory duration discrimination. J Speech Hear Res 37:662-670. CrossRef Medline

Goldberg JM, Brown PB (1969) Response of binaural neurons of dog superior olivary complex to dichotic tonal stimuli: some physiological mechanisms of sould localization. J Neurophysiol 32:613-636. Medline

Gordon-Salant S (2014) Aging, hearing loss, and speech recognition: stop shouting, I can't understand you. In: Perspectives on auditory research (Popper AN, Fay RR, eds), pp 211-228. New York: Springer.

Gratton MA, Schmiedt RA, Schulte BA (1996) Age-related decreases in endocochlear potential are associated with vascular abnormalities in the stria vascularis. Hear Res 102:181-190. CrossRef Medline

Gratton MA, Schulte BA, Smythe NM (1997) Quantification of the stria vascularis and strial capillary areas in quiet-reared young and aged gerbils. Hear Res 114:1-9. CrossRef Medline

Gutiérrez A, Khan ZU, Morris SJ, De Blas AL (1994) Age-related decrease of GABAA receptor subunits and glutamic acid decarboxylase in the rat inferior colliculus. J Neurosci 14:7469-7477. Medline

Harris KC, Wilson S, Eckert MA, Dubno JR (2012) Human evoked cortical activity to silent gaps in noise: effects of age, attention, and cortical processing speed. Ear Hear 33:330-339. CrossRef Medline

Helfer KS, Freyman RL (2014) Stimulus and listener factors affecting agerelated changes in competing speech perception. J Acoust Soc Am 136: 748-759. CrossRef Medline

Humes LE, Dubno JR, Gordon-Salant S, Lister JJ, Cacace AT, Cruickshanks KJ, Gates GA, Wilson RH, Wingfield A (2012) Central presbycusis: a review and evaluation of the evidence. J Am Acad Audiol 23:635-666. CrossRef Medline

Ingham NJ, Comis SD, Withington DJ (1999) Hair cell loss in the aged guinea pig cochlea. Acta Otolaryngol 119:42-47. CrossRef Medline

Jordan D, Ilg R, Riedl V, Schorer A, Grimberg S, Neufang S, Omerovic A, Berger S, Untergehrer G, Preibisch C, Schulz E, Schuster T, Schröter M, Spoormaker V, Zimmer C, Hemmer B, Wohlschläger A, Kochs EF, Schneider G (2013) Simultaneous electroencephalographic and functional magnetic resonance imaging indicate impaired cortical top-down processing in association with anesthetic-induced unconsciousness. Anesthesiology 119:1031-1042. CrossRef Medline

Joris PX, Schreiner CE, Rees A (2004) Neural processing of amplitudemodulated sounds. Physiol Rev 84:541-577. CrossRef Medline

Kalappa BI, Brozoski TJ, Turner JG, Caspary DM (2014) Single unit hyperactivity and bursting in the auditory thalamus of awake rats directly correlates with behavioural evidence of tinnitus. J Physiol 592:5065-5078. CrossRef Medline

Keithley EM, Ryan AF, Woolf NK (1989) Spiral ganglion cell density in young and old gerbils. Hear Res 38:125-133. CrossRef Medline

Keithley EM, Ryan AF, Feldman ML (1992) Cochlear degeneration in aged rats of four strains. Hear Res 59:171-178. CrossRef Medline

Kraus N, McGee T, Carrell TD, King C, Tremblay K, Nicol T (1995) Central auditory system plasticity associated with speech discrimination training. J Cogn Neurosci 7:25-32. CrossRef Medline

Krenning J, Hughes LF, Caspary DM, Helfert RH (1998) Age-related glycine receptor subunit changes in the cochlear nucleus of Fischer-344 rats. Laryngoscope 108:26-31. CrossRef Medline

Lee HJ, Wallani T, Mendelson JR (2002) Temporal processing speed in the inferior colliculus of young and aged rats. Hear Res 174:64-74. CrossRef Medline

Lesicko AM, Llano DA (2016) Impact of peripheral hearing loss on top-down auditory processing. Hear Res pii:S0378-5955(16)30105-8. CrossRef Medline

Leung AW, He Y, Grady CL, Alain C (2013) Age differences in the neuroelectric adaptation to meaningful sounds. PLoS One 8:e68892. CrossRef Medline

Ling LL, Hughes LF, Caspary DM (2005) Age-related loss of the GABA synthetic enzyme glutamic acid decarboxylase in rat primary auditory cortex. Neuroscience 132:1103-1113. CrossRef Medline

Llano DA (2013) Functional imaging of the thalamus in language. Brain Lang 126:62-72. CrossRef Medline

Lu T, Liang L, Wang X (2001) Temporal and rate representations of timevarying signals in the auditory cortex of awake primates. Nat Neurosci 4:1131-1138. CrossRef Medline

Lumani A, Zhang H (2010) Responses of neurons in the rat's dorsal cortex of the inferior colliculus to monaural tone bursts. Brain Res 1351:115129. CrossRef Medline

Malmierca MS, Anderson LA, Antunes FM (2015) The cortical modulation of stimulus-specific adaptation in the auditory midbrain and thalamus: a potential neuronal correlate for predictive coding. Front Sys Neurosci 9:19. CrossRef Medline

Mardia KV, Jupp PE (2000) Directional statistics. New York: Wiley.

Mashour GA (2014) Top-down mechanisms of anesthetic-induced unconsciousness. Front Sys Neurosci 8:115. CrossRef Medline

Mattys SL, Scharenborg O (2014) Phoneme categorization and discrimination in younger and older adults: a comparative analysis of perceptual, lexical, and attentional factors. Psychol Aging 29:150-162. CrossRef Medline

Mendelson JR, Lui B (2004) The effects of aging in the medial geniculate 
nucleus: a comparison with the inferior colliculus and auditory cortex. Hear Res 191:21-33. CrossRef Medline

Mendelson JR, Ricketts C (2001) Age-related temporal processing speed deterioration in auditory cortex. Hear Res 158:84-94. CrossRef Medline

Milbrandt JC, Albin RL, Caspary DM (1994) Age-related decrease in GABAB receptor binding in the Fischer 344 rat inferior colliculus. Neurobiol Aging 15:699-703. CrossRef Medline

Milbrandt JC, Albin RL, Turgeon SM, Caspary DM (1996) GABAA receptor binding in the aging rat inferior colliculus. Neuroscience 73:449-458. CrossRef Medline

Moore BC, Peters RW, Glasberg BR (1992) Detection of temporal gaps in sinusoids by elderly subjects with and without hearing loss. J Acoust Soc Am 92:1923-1932. CrossRef Medline

Nelken I (2014) Stimulus-specific adaptation and deviance detection in the auditory system: experiments and models. Biol Cybern 108:655-663. CrossRef Medline

Nir Y, Vyazovskiy VV, Cirelli C, Banks MI, Tononi G (2015) Auditory responses and stimulus-specific adaptation in rat auditory cortex are preserved across NREM and REM sleep. Cereb Cortex 25:1362-1378. CrossRef Medline

Ostroff JM, McDonald KL, Schneider BA, Alain C (2003) Aging and the processing of sound duration in human auditory cortex. Hear Res 181: 1-7. CrossRef Medline

Palombi PS, Caspary DM (1996a) GABA inputs control discharge rate primarily within frequency receptive fields of inferior colliculus neurons. J Neurophysiol 75:2211-2219. Medline

Palombi PS, Caspary DM (1996b) Responses of young and aged Fischer 344 rat inferior colliculus neurons to binaural tonal stimuli. Hear Res 100: 59-67. CrossRef Medline

Palombi PS, Caspary DM (1996c) Physiology of the aged Fischer 344 rat inferior colliculus: responses to contralateral monaural stimuli. J Neurophysiol 76:3114-3125. Medline

Parthasarathy A, Lai J, Bartlett EL (2016) Age-related changes in processing simultaneous amplitude modulated sounds assessed using envelope following responses. J Assoc Res Otolaryngol 17:119-132. CrossRef Medline

Paxinos W, Watson C (1998) The rat brain in stereotaxic coordinates. San Diego: Academic.

Rabang CF, Bartlett EL (2011) A computational model of cellular mechanisms of temporal coding in the medial geniculate body (MGB). PLoS One 6:e29375. CrossRef Medline

Raza A, Milbrandt JC, Arneric SP, Caspary DM (1994) Age-related changes in brainstem auditory neurotransmitters: measures of GABA and acetylcholine function. Hear Res 77:221-230. CrossRef Medline

Richardson BD, Ling LL, Uteshev VV, Caspary DM (2013a) Reduced $\mathrm{GABA}_{\mathrm{A}}$ receptor-mediated tonic inhibition in aged rat auditory thalamus. J Neurosci 33:1218-1227a. CrossRef Medline

Richardson BD, Hancock KE, Caspary DM (2013b) Stimulus-specific adaptation in auditory thalamus of young and aged awake rats. J Neurophysiol 110:1892-1902. CrossRef Medline

Rodgers CC, DeWeese MR (2014) Neural correlates of task switching in prefrontal cortex and primary auditory cortex in a novel stimulus selection task for rodents. Neuron 82:1157-1170. CrossRef Medline

Saitoh Y, Hosokawa M, Shimada A, Watanabe Y, Yasuda N, Takeda T, Murakami Y (1994) Age-related hearing impairment in senescenceaccelerated mouse (SAM). Hear Res 75:27-37. CrossRef Medline

Schmiedt RA, Mills JH, Boettcher FA (1996) Age-related loss of activity of auditory-nerve fibers. J Neurophysiol 76:2799-2803. Medline

Schneider BA, Pichora-Fuller MK, Kowalchuk D, Lamb M (1994) Gap detection and the precedence effect in young and old adults. J Acoust Soc Am 95:980-991. CrossRef Medline
Shaddock Palombi P, Backoff PM, Caspary DM (2001) Responses of young and aged rat inferior colliculus neurons to sinusoidally amplitude modulated stimuli. Hear Res 153:174-180. CrossRef Medline

Skoe E, Kraus N (2010) Hearing it again and again: on-line subcortical plasticity in humans. PLoS One 5:e13645. CrossRef Medline

Skoe E, Chandrasekaran B, Spitzer ER, Wong PC, Kraus N (2014) Human brainstem plasticity: the interaction of stimulus probability and auditory learning. Neurobiol Learn Mem 109:82-93. CrossRef Medline

Snell KB (1997) Age-related changes in temporal gap detection. J Acoust Soc Am 101:2214-2220. CrossRef Medline

Spongr VP, Flood DG, Frisina RD, Salvi RJ (1997) Quantitative measures of hair cell loss in CBA and C57BL/6 mice throughout their life spans. J Acoust Soc Am 101:3546-3553. CrossRef Medline

Stebbings KA, Lesicko AM, Llano DA (2014) The auditory corticocollicular system: molecular and circuit-level considerations. Hear Res 314:51-59. CrossRef Medline

Stebbings KA, Choi HW, Ravindra A, Caspary DM, Turner JG, Llano DA (2016) Ageing-related changes in GABAergic inhibition in mouse auditory cortex, measured using in vitro flavoprotein autofluorescence imaging. J Physiol 594:207-221. CrossRef Medline

Strouse A, Ashmead DH, Ohde RN, Grantham DW (1998) Temporal processing in the aging auditory system. J Acoust Soc Am 104:2385-2399. CrossRef Medline

Tang X, Zhu X, Ding B, Walton JP, Frisina RD, Su J (2014) Age-related hearing loss: GABA, nicotinic acetylcholine and NMDA receptor expression changes in spiral ganglion neurons of the mouse. Neuroscience 259: 184-193. CrossRef Medline

Tremblay KL, Piskosz M, Souza P (2002) Aging alters the neural representation of speech cues. Neuroreport 13:1865-1870. CrossRef Medline

Tremblay KL, Piskosz M, Souza P (2003) Effects of age and age-related hearing loss on the neural representation of speech cues. Clin Neurophysiol 114:1332-1343. CrossRef Medline

Turner JG, Hughes LF, Caspary DM (2005) Affects of aging on receptive fields in rat primary auditory cortex layer V neurons. J Neurophysiol 94:2738-2747. CrossRef Medline

Ulanovsky N, Las L, Nelken I (2003) Processing of low-probability sounds by cortical neurons. Nat Neurosci 6:391-398. CrossRef Medline

von der Behrens W, Bäuerle P, Kössl M, Gaese BH (2009) Correlating stimulus-specific adaptation of cortical neurons and local field potentials in the awake rat. J Neurosci 29:13837-13849. CrossRef Medline

Walton JP, Simon H, Frisina RD (2002) Age-related alterations in the neural coding of envelope periodicities. J Neurophysiol 88:565-578. Medline

Wang H, Brozoski TJ, Turner JG, Ling L, Parrish JL, Hughes LF, Caspary DM (2009) Plasticity at glycinergic synapses in dorsal cochlear nucleus of rats with behavioral evidence of tinnitus. Neuroscience 164:747-759. CrossRef Medline

Wang X, Lu T, Bendor D, Bartlett E (2008) Neural coding of temporal information in auditory thalamus and cortex. Neuroscience 157:484-494. CrossRef Medline

Willott JF, Parham K, Hunter KP (1991) Comparison of the auditory sensitivity of neurons in the cochlear nucleus and inferior colliculus of young and aging C57BL/6J and CBA/J mice. Hear Res 53:78-94. CrossRef Medline

Yaron A, Hershenhoren I, Nelken I (2012) Sensitivity to complex statistical regularities in rat auditory cortex. Neuron 76:603-615. CrossRef Medline

Yin P, Johnson JS, O'Connor KN, Sutter ML (2011) Coding of amplitude modulation in primary auditory cortex. J Neurophysiol 105:582-600. CrossRef Medline 